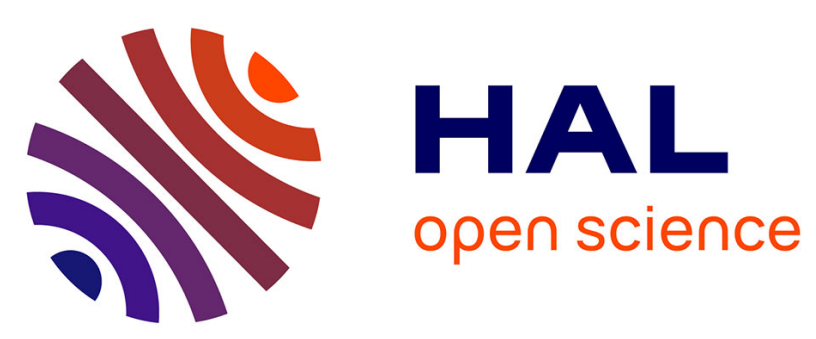

\title{
How to keep your horse safe? An epidemiological study about management practices
}

Clémence Lesimple, Alexandre Poissonnet, Martine Hausberger

\section{To cite this version:}

Clémence Lesimple, Alexandre Poissonnet, Martine Hausberger. How to keep your horse safe? An epidemiological study about management practices. Applied Animal Behaviour Science, 2016, 181, pp.105-114. 10.1016/j.applanim.2016.04.015 . hal-01332171v2

\section{HAL Id: hal-01332171}

https://hal-univ-rennes1.archives-ouvertes.fr/hal-01332171v2

Submitted on 14 Sep 2016

HAL is a multi-disciplinary open access archive for the deposit and dissemination of scientific research documents, whether they are published or not. The documents may come from teaching and research institutions in France or abroad, or from public or private research centers.
L'archive ouverte pluridisciplinaire HAL, est destinée au dépôt et à la diffusion de documents scientifiques de niveau recherche, publiés ou non, émanant des établissements d'enseignement et de recherche français ou étrangers, des laboratoires publics ou privés. 
3

4

5

6

7

How to keep your horse safe? An epidemiological study about management practices Lesimple, $\mathrm{C}^{1}$., Poissonnet, $\mathrm{A}^{1}$., Hausberger, $\mathrm{M}^{2}$.

${ }^{1}$ Université de Rennes 1, Ethologie Animale et Humaine UMR CNRS 6552, Bâtiment 25, Campus de Beaulieu, 263 Avenue du General Leclerc, CS 74205, 35042 Rennes Cedex, France

${ }^{2}$ CNRS, Ethologie Animale et Humaine UMR 6552 Université de Rennes1, Bâtiment 25, Campus de Beaulieu, 263 Avenue du General Leclerc, CS 74205, 35042 Rennes Cedex, France * corresponding author: lesimple.c@gmail.com, phone: +3322323 30 45, fax: +3322323 69 27, Université Rennes 1, UMR CNRS 6552 Ethologie Animale et Humaine, Bâtiment 25, Campus de Beaulieu, 263 Avenue du General Leclerc, 35042 Rennes Cedex, France

\section{Abstract}

As animal welfare has become a major societal concern since the last decades, identifying the factors affecting it, is of first importance. Many studies have been conducted, mostly centred on one particular environmental factor. However, animal welfare is multifactorial, and evaluating the management as a whole seems more appropriate. In this particular study, we aimed to identify environmental parameters impacting riding school horses' welfare. We focused here on four reliable welfare indicators (presence of wounds, stereotypic/abnormal repetitive behaviours, ear position and depressed-like posture) and recorded sixteen intrinsic (e.g. sex, age, type) and extrinsic (housing, feeding, social and working conditions) factors of impact. Using logistic regression models, we could identify and classify the management parameter according to their impact on the different welfare indicators and we were able to identify characteristics of good and bad management practices. Besides confirming the importance of feeding and housing conditions, our study is the very first to show that working conditions in developed countries have a crucial impact on several aspects of equines' welfare, and that horses might be less resilient to inappropriate living conditions than ponies. This study leads to the identification of characteristics of "good" and "bad" management practices as a whole, based on scientific evidences on a large sample of horses.

Key words: equids, welfare, management, work, equid type 


\section{Introduction}

Assessing the factors influencing animal welfare has been the core of many scientific studies in the last decades. Most of them have been centered on one particular potential factor of influence (i.e. housing : e.g. Casamassima et al 2001, Meunier-Salaun et al 1987; social conditions: e.g. Grignard et al 2000, van Reenen et al 2000, Bouissou et al 2001, Wechsler et al 1997; feeding: e.g. Freire et al 2009), whereas only a multifactorial approach, including a maximum of management parameters, could allow an overview of the real consequences on animal welfare. The welfare state of an individual results from a combination of influences and there is a strong need to develop systemic and hence large scale "field" studies (Main et al., 2003; Whay et al., 2003) in order to reliably evaluate (and thus improve) the animals' welfare. The relative weight of the different factors and their potential interactions are of prime interest if improvements are to be proposed in management practices.

Some attempts have been made in horses (Mc Greevy et al., 1995), but because assessing animal welfare through a large scale is energy and time consuming, most of these studies rely upon questionnaire surveys of caretakers or owners' opinions (Napolitano et al.,, 2008; Parker et al., 2008; Upjohn et al., 2012). These studies have emphasized the impact of some crucial factors such as food availability and composition, early experience, social possibilities or stabling, on the prevalence of chronic behavioural problems such as stereotypic behaviours (Hockenhull and Creighton, 2010; McBride and Long, 2001; Mc Greevy et al., 1995; Normando et al., 2002; Parker et al. 2008; Visser et al 2008; Waters et al., 2002). More recently, a study including equitation factors (riding style, e.g. western or english and number of working hours per week) showed that riding style has a major impact on the prevalence of chronic behavioural problems (Normando et al., 2011), confirming observational studies (Hausberger et al., 2009, 2011).

Although these surveys have proved very useful in identifying factors of influence, they often focus on one particular welfare indicator (e.g. stereotypic behaviour), rely upon subjective assessment of caretakers or owners and depend on the respondents' "ability" to assess the target welfare indicator and / or on their willingness to admit their horses' behavioural problems (Mills et al., 2002; Lesimple and Hausberger, 2014). If in one study, experimenter's observations and responses of owners did converge on the prevalence of stereoptypic behaviours (Normando et al., 2011), discrepancy between the actual prevalence and the 
owners' / caretakers' evaluations may be huge (Lesimple and Hausberger 2014). This is especially true in stables highly "at risk" (70-100\% of stereotypic horses) where overexposure of owners/caretakers to abnormal behaviour or signs of poor welfare prevents proper evaluation (Lesimple and Hausberger 2014). This may explain why estimates of the prevalence of stereotypic and abnormal repetitive behaviours are between 1 and 10\% according to questionnaire surveys (McGreevy et al., 1995; Mills et al., 2002; Normando al., 2011; Parker et al., 2008) and between 22 and 96.6\% in observational studies (Benhajali et al., 2010, 2014; Fureix et al., 2011; Hausberger et al. 2007, 2009; Lesimple and Hausberger 2014; Visser et al., 2008). In the same way, effects of the rider-based parameters (e.g. the rider's position) can only be explored using observational studies (Hockenhull and Creighton, 2012). Some large scale observational studies have been performed: Pritchard et al. (2005) and Burn et al. (2010a, 2010b) analysed data from several thousand of equids from different countries. Welfare assessment was performed by trained observers on the basis of 3 types of measures: physical health, alertness and response to human actions. This approach appeared to be very promising, revealing for example that apathetic horses were overall in poor health and presented more body lesions. Because these studies require that assessment be quick, noninvasive and easy to apply in "field" conditions (no disturbance in the facilities' routines), the parameters used need to be both simple and rapid to assess.

In the present study, we carried out an epidemiological study on a large sample of riding school horses living in facilities distributed all over France. We chose, as most of the abovementioned studies, animal-based measures previously shown to be reliable welfare indicators, obtained through direct observations in the horses' home environment. The welfare assessment was based on clearly defined indicators and measures: body lesions, abnormal behaviours, alertness and postures (see also Hausberger et al., 2016). They were chosen because the evaluation needed to be easily and rapidly performed in the facilities ( 3 days/facility). The aim was to evaluate the relative weight of different parameters, either intrinsic (age, breed, sex) or extrinsic (housing, feeding or social related) on horses' welfare state (this study), but also to be able to compare facilities' management as whole systems, and not parameter by parameter.

\section{Material and methods}

The present study was divided into two parts: a first part on 306 horses from 20 riding schools for which "classical" management parameters (housing, feeding and social conditions) were examined and a second part on a subset of 276 horses for which we also had information on 
the riding techniques used in the facility. The second part includes therefore elements that were proven to be crucial for the horses' back health in earlier studies (Lesimple et al., 2010, subm). Logistic regressions provided multivariate models that allowed a ranking of the factors of influence (e.g. Benhajali et al., 2010; Normando et al., 2011, Visser et al., 2014). The study was performed between October 2010 and May 2011. The observations were conducted in 20 riding schools ( $\mathrm{N}=306$ horses, 2 stallions, 177 geldings and 127 mares) all over France. Detailed information on the specific population studied in each part of the studies is given below.

\subsection{Animal based measures and data sampling}

\subsubsection{Physical/health indicator}

Several studies conducted in developing countries measured the animals' body score in order to have an evaluation of their physical state (Pritchard et al., 2005; Burn et al., 2010b, Popescu and Diugan 2013). However, in our population of French riding school horses, all the animals scored in a pilot study were "optimal" to "fat" and the measurement of body condition was not discriminant (Fureix in prep). Therefore we did not include body scoring in our welfare measures.

- Body lesions related to the equipment: in horses working under extreme environmental conditions (e.g. high heat, dehydration), the presence of wounds related to bad equipment's fitting is associated with reveals a more general poor welfare state and is related to the development of strong apathetic states (e.g. Burn et al 2010a). Each equid involved in the study was thoroughly examined and an exhaustive list of the wounds or marks of former wounds (white hair areas) and their relative location compared to the equipment (place of the saddle, girth, bit/bridle, spurs) was noted (Burn et al 2010a, 2010b, Popescu \& Diugan 2013, Pritchard et al 2005). Horses presented only minor flesh wounds, mostly hairs removed and sometimes some slight skin irritation. Horses were then binary classified: 1 if they presented at least one lesion (or mark of former lesion) and 0 otherwise.

\subsubsection{Behavioural measures}

\section{- Stereotypic / Abnormal Repetitive Behaviours}

Stereotypic and abnormal repetitve behaviours are repetitive, invariant and (apparently) functionless behaviours (Mason, 1991; Ödberg, 1978), that are never seen in animals under natural conditions and are known to appear in captivity under sub-optimal conditions (Mason, 1991). In most species, the presence of such behaviours is associated with chronic stress (Bashaw et al., 2001; Keiper, 1969; Meehan et al., 2004) and their emergence is linked to 
repeated contexts of frustration (e.g. Fureix et al., 2011; Benhajali et al., 2014). Environmental restrictions, including feeding (e.g. McGreevy et al., 1995; Nicol, 2000), social (e.g. Cooper et al., 2000; Mills and Riezebos, 2005), spatial (e.g. McGreevy et al., 1995; Parker et al., 2008) and working (Hausberger et al 2009) conditions appear as facilitating factors, as is genetic influence (e.g. Vecchioti and Galanti, 1986). Some horses persist in performing these behaviours even after the conditions have improved, which means that if one horse performs them in a stable, this does not mean the management practices are inappropriate. However, the large number of horses involved here prevent the influence of such particular cases on the statistically significant management practices. Their presence in horses is associated with a decrease of learning abilities (Hausberger et al., 2007; Parker et al., 2008) and fertility (Benhajali et al., 2014).

To facilitate the reading, we will define here the terms used in the following manuscript. We call here "stereotypic behaviours" (SB) the sequences well-known in the horse industry (e.g. weaving, cribbing) and "abnormal repetitive behaviours" (ARB) the sequences less (not) described or recognized (Mills 2005, Mills et al, 2002). As they share the same definition (repetitive and apparently functionless behaviours) and appear under sub-optimal conditions, they were grouped in the subsequent analyses (SB/ARB). The $5 \mathrm{SB}$ and the 9 ARB observed or reported in this study are described below.

SB (from Mills, 2005; Lesimple and Hausberger, 2014):

- weaving: obvious lateral movement of head, neck, forequarters and sometimes hindquarters, - cribbing / windsucking: the horse grasps a fixed object with its incisors, pulls backwards and draws air into its oesophagus,

- head tossing / nodding: vertical movements of head and neck,

- striking with forelimb: the horse hits the door or wall with one of its forelegs,

- box walking: repetitive tracing a route within the stable.

ARB

- compulsive licking: licking of the same object in its environment (except the trough),

- compulsive biting: biting of the same object in its environment (except the trough),

- head movements (other than head tossing / nodding): movement of the head,

- Vacuum threats: the horse express threat sequences (kicking, biting) alone in its box,

- mouth open: the horse keeps its mouth open with a lateral movement of its neck,

- teeth rubbing: rubbing teeth on the upper part of the door,

- teeth chattering: mouth movement with teeth chattering,

- lips movements: clapping of lips, 
- tongue movements: movements of tongue, inside or outside the mouth In the present study, the observer (C.L) stood motionless at one end or in the middle of lines of boxes so that she could see all horses. In many cases, the stables were disposed along corridors with a row of stalls on each side. When positioned at the midline of the corridor, it was therefore possible to easily see 4 stalls at a time. When the stables were so that the stalls had an opening outside, it was generally possible to see 6 horses in a row. The sampling was ad libitum (Altman 1974, Benhajali et al 2008, Lesimple \& Hausberger 2014) which means that the behaviours concerned were scored (in terms of presence/absence) everytime they occurred together with the horse identity. For a behaviour to be considered as SB/ARB, the behavioural sequence had to be repeated at least 3 times successively and observed 5 times, independently of the period of observation. Most observations were performed at quiet times (outside teaching activities) with little disturbance by the routine procedures. In any case, the proportion of quiet and disturbed time periods was balanced between stables so that they remained comparable. In total, each horse was observed for 18 hours. At the end of the procedure, horses were binary scored: 1 if they performed at least one SB/ARB, 0 otherwise.

\subsubsection{Postural measures}

- Depressed-like posture (AbnPost) with or without wall orientation: Apathetic animals, showing a strong decrease of reactions towards their environment, were described in several situations when welfare was altered (Burn et al 2010a, 2010b, Popescu and Diugan 2013) particularly in cases of proven pain (Hausberger et al 2016). Fureix et al (2012) were the first to truly characterize this "depressive-like" state in riding school horses: the animals stand immobile, eyes wide opened with a stretched neck (back and neck on the same line), an unusual gaze, head and ears fixity, mostly backwards ears and a global indifference towards environmental stimuli (visual, tactile and auditory, Fureix et al., 2012; Rochais et al. 2015, subm) in their home environment. Such horses also show signs of anhedonia (Fureix et al 2015).

The prevalence of "depressed like posture" was evaluated at the same time as SB/ARB and following the exact same procedure. At the end of the observation time (18h/horse, see above), horses were binary classified: 1 if they presented at least once the "depressed-like" posture" during the observation time, 0 otherwise.

- Ears position: Backwards ears position is reported in all cases of acute pain or discomfort (Hausberger et al 2016 for a review, Waring, 2003) and has been shown to indicate welfare impairment in horses (Fureix et al 2010, in prep). In these studies, a 
predominant backwards ears position ( $>50 \%$ time) was related to an increased prevalence of stereotypic behaviours and chronic health problems, while forwards ears indicated either a positive human-horse relationship, an increased attentional state towards the environment and overall a better welfare (Hausberger and Müller, 2002; Rochais et al., 2016, Waring, 2003). Ears positions were defined by referring to studies on other species (Reefmann et al 2009): axial ear (perpendicular to the head - rump axis), forward ear (tip of the ear towards the front at an angle of more than $30^{\circ}$ from the perpendicular) or backward ear (tip of the ear towards the back at more than $30^{\circ}$ from the perpendicular).

Ear positions were recorded whilst horses were foraging on the ground (hay/straw) only, as it has been shown to be the most reliable context (Fureix et al 2010, in prep.). Observations were performed when the stables were quiet, outside feeding and working time. The experimenter walked slowly and regularly $(1 \mathrm{step} / \mathrm{sec})$ in the middle of the corridor, or $2 \mathrm{~m}$ away from the boxes in stables with one line of boxes. She approached slowly towards each box in order to be able to see the ear positions through the trough opening or box's door, remaining at a distance. This quiet approach did not elicit the strong reactions observed when approaching suddenly at the box's door (Hausberger and Muller 2002). The instantaneous ear position of the feeding horse was silently noted (only if the horse kept feeding and paid no attention to the observer). The observer then resumed her walk along the midline up to the next stall. These samplings were made every day for 3 consecutive days and distributed all along the day until 10 ear positions were obtained per horse. The percentage of scans in each position was calculated for each horse. For further analyses horses were binary categorized according to their "favourite" ( $\geq 60 \%)$ posture: mostly forwards ears / mostly backwards ears. Asymmetric or side positions were considered as "neutral" and were in any case observed much less often.

Based on these observations, each animal was binary classified for each of the welfare impairment signal.

\subsection{Management parameters (Tables 1 and 2)}

All the horses involved in the study were under the responsibility of the riding schools and subjected to the standard living conditions of the facilities. For the needs of the analyses, the management parameters had to be categorical. All these management parameters are detailed below.

\subsubsection{Choice of horses: type of equids present}


The sex, age and breed were recorded from the animals' official identification documents. However, since most animals were unregistered, the 'breed' parameter could not be used as such. Differences have been observed between types of equids (e.g. pony / horses, "warmbloods"/ "coldbloods") in other studies (e.g. Wallin et al., 2000), meaning that above breed, several types of equids may exist, that differ in different traits. Therefore, we investigated two features: the equid's overall morphology, and its size. Using the parameters described in Chabchoub et al (2004), we classified the animals into 3 categories, based on their proportion: dolichomorphic (length>height, ex: thoroughbred, Arab purebred), mesomorphic (length=height, ex: French saddlebred) and brachymorphic (length $<$ height: Merens horses). The animals were also divided into "classical" official type: pony $(<1.48 \mathrm{~m}$ high at the withers, International Federation for Equestrian Sport) or horse ( $>1.48 \mathrm{~m}$ high at the withers) in the analyses. The impact of the animal's age was also investigated ([3-10], [1115], [16+] y.o.).

\subsubsection{Housing conditions}

The spatial restriction being an important aspect in horse welfare (Raabygmagle and Ladewig, 2006; Rivera et al., 2002; Parker et al., 2008) the size of the boxes and the percentage of time spent in paddock were recorded for each individual. In France, standard boxes are 9, 12 or $16 \mathrm{~m}^{2}$ wide. As in this study, most boxes measured $9 \mathrm{~m}^{2}$, two categories were made: small $\left(\leq 9 \mathrm{~m}^{2}\right)$ and big $\left(>9 \mathrm{~m}^{2}\right)$. Depending of the facility, equids spent 0 to $83.3 \%(\bar{X} \pm \mathrm{es}=19.5 \pm 1.3)$ of their time in paddocks. According to the data distribution, two profiles appeared: horses went in paddock either less than $17 \%$ or more than $25 \%$ of their time. These values were used to make the categories. The bedding (straw or shaving) (Pedersen et al., 2004), as well as the box architecture and in particular the visual horizon of the horses (Benhajali et al., subm; Cooper et al., 2000; Hausberger et al., subm), were recorded: thus it was noted whether equids could put the head outside the box (entirely: open doors, limited: V shape doors, or not: grids) and if the box was open to the outside or inside a building.

\subsubsection{Social conditions}

All the animals in this study could at least hear one congener. For each individual, we recorded whether or not they could have tactile contact with one of their neighbours when in the box, and we also recorded the number of visible congeners from inside the box (e.g. Mills \& Riezebos 2005). The number of visible neighbours was divided into 3 categories ([01], [2-4], [5+]) according to the distribution of the data. When the animals had access to a paddock, we also recorded whether they went alone or in group.

\subsubsection{Feeding conditions}


For each individual, the quantity and number of meals of roughage and concentrates was recorded from the instruction documents of the facilities (e.g. Nicol, 2000). As in both cases, the two parameters were strongly correlated (Spearman correlation test, $p<0.0001$ ), only the number of meals, giving information on the temporal distribution of feeding (Benhajali et al., 2009, 2013; Fureix et al., 2011) were kept in the analysis. Based on the data distribution, roughage availability was divided into 4 categories ([0]: no roughage, [1]: once/day, [2]: twice/day, [3-10]: almost continuous) and concentrate availability into 3 categories ([0]: no concentrates, [1-2]: few concentrates, [3-6]: large amount of concentrates).

\subsubsection{Working conditions}

First, we extracted the time spent working/ week for each equid from the official working document of the schools. Based on the data distribution, 3 categories were made: [5-7], [810], [11-14] h/week.

\subsection{Statistical analyses}

Logistic regressions models were used to assess the impact of the management factors on each of the welfare indicators. The first step was the selection of the management factors that would integrate the model, using univariate logistic regressions. Thus, each of the 15 management factors was tested on each of the 5 welfare indicators. For each welfare indicator, all the factors with a $\mathrm{p}$ value $<0.2$ were kept to build the logistic models. The second step was to integrate the selected management factors in multivariate logistic regression models with a stepwise function to settle the most explicative factor combination. A F test was conducted to assess the significance of the management factors kept in the model. The F value was used to assess the importance of the management factor in the model. All the modalities of each management factor were defined by a coefficient (coef) and an Odd Ratio (OR). The OR for the modality of reference (used as base in the analyses) is 1 . The other modalities are compared to this reference. The OR. was used to determine the "direction" of action (increasing or decreasing the prevalence of the indicator) and the coeff was used to assess the impact of the different modalities. To assess the relative importance (RI) of each of the modalities of all management factors involved in the model, we used the exponential function of the coefficient. Each OR was accompanied with a 95\% Confidence Interval (IC). If 1 was comprised in the IC, the modality could not be considered as significant.

In a first step, we did simple models without taking into account interactions. Then, as ponies are traditionally kept under less constraining conditions, we included the interactions between 
the type of equine (pony/horse) and the other management practices. All the interactions with a p value $<0.2$ were kept in the models.

Chi square post hoc tests were used to assess further differences between several modalities of the same management factor.

All the statistical analyses were made using R 3.1.1. software.

\section{Results}

To facilitate the reading, when describing the logistic regression models, only the significant parameters will be presented.

\subsection{Study 1: Impact of life conditions and choice of equids}

\subsubsection{Population}

For the first part of this study, 306 horses (2 stallions, 177 geldings and 127 mares) of various ages (3-34y.o, $\left.\bar{X}_{ \pm \mathrm{se}}=12.2 \pm 0.28\right)$ and breeds $(\mathrm{N}=23$, mostly unregistered horses: $36.6 \%$ and French Saddlebreds: $26 \%$ with smaller proportions of other breeds) in 20 riding schools all over France $\left(\bar{X}_{ \pm}\right.$se $=15.3 \pm 0.48$ horse/school $)$ were observed. Most of the animals were horses (>1.48m at withers, $\mathrm{N}=191,62.4 \%)$ and $115(37.6 \%)$ were ponies $(<1.48 \mathrm{~m}$ at withers) Amongst these 306 horses, $67.6 \%(\mathrm{~N}=207)$ presented equipment-related wounds, 35\% $(\mathrm{N}=107)$ expressed at least one STB/ARB, 38\% ( $=116)$ had mostly backwards ears $(>60 \%$ time) $(36 \%(\mathrm{~N}=110)$ had mostly forwards ears) and $41.5 \%(\mathrm{~N}=127)$ presented a "depressedlike" posture in the box.

\subsubsection{Presence of equipment-related wounds}

Three main management parameters appeared to have a significant impact on the prevalence of equipment-related wounds: the time spent in paddock $(F=7.77, p=0.003)$, the type of equine $(\mathrm{F}=4.59, \mathrm{p}=0.02)$ and the number of hay meals $(\mathrm{F}=3.75, \mathrm{p}=0.01)$. Thus, animals that spent less time in paddock (Odd Ratio [Interval of Confidence] $=2.37$ [1.35-4.18]), were of horse type (OR [IC] = 1.87 [1.1-3.2]) and received few (0: OR [IC] = 2.44 [1.03-5.80], or 1: OR [IC] = 2.29 [1.26-4.16]) hay meals were more prone to have wounds. On the contrary, there were less such wounds in animals that spent more than $25 \%$ of time in paddock (reference modality, $\mathrm{OR}=1)$, being a pony $(\mathrm{OR}=1)$ and having 2 hay meals $(\mathrm{OR}=1)$ (Table 1.).

The most important parameter appeared to be the time spent in paddock $(\mathrm{RI}=2.36)$, followed by the number of hay meals ( $\mathrm{RI}=2.29)$ and the type of equid $(\mathrm{RI}=1.88)$. 
When interactions were included in the model, it appeared that horses were more prone than ponies to have wounds if they spent less than $25 \%$ time in paddocks $(\mathrm{F}=3.97, \mathrm{p}=0.05$, OR $[\mathrm{IC}]=3.27[1.1-9.69])$.

\subsubsection{Presence of SB/ARB}

Four parameters appeared to impact the prevalence of SB/ ARB: the time spent in paddock $(\mathrm{F}=14.12, \mathrm{p}=0.0002)$, the type of equine $(\mathrm{F}=8.6, \mathrm{p}=0.004)$, the possibility to put the head outside the box $(\mathrm{F}=4.31, \mathrm{p}=0.01)$ and the number of concentrate meals $(\mathrm{F}=3.25, \mathrm{p}=0.04)$. The animals that spent less time in paddock (OR [IC] =3.69 [1.88-7.22]), were of horse type $(\mathrm{OR}[\mathrm{IC}]=2.56$ [1.39-4.69]), could put the head outside the box $(\mathrm{OR}=1)$ and had more concentrate meals $(\mathrm{OR}=1)$ were more prone to develop SB/ARB. On the contrary, spending at least $25 \%$ time in paddock $(\mathrm{OR}=1)$, being a pony $(\mathrm{OR}=1)$, having limited $(\mathrm{OR}[\mathrm{IC}]=0.44$ $[0.22-0.85])$ or no $(\mathrm{OR}[\mathrm{IC}]=0.38[0.15-0.96])$ possibilities to put the head outside the box and having no concentrate meals (OR $[\mathrm{IC}]=0.12[0.01-0.95])$ reduced the risk of developing SB/ARB.

The most important parameter appeared to be the number of concentrate meals $(\mathrm{RI}=8.67)$, followed the time spent in paddock $(\mathrm{RI}=3.71)$, the possibility to put the head outside the box (RI=2.66), and the type of equid ( $\mathrm{RI}=2.56)$.

When integrating interactions in the model, it appeared that being released alone in paddock increased more the risk of presenting SB/ARB for horses than for ponies $(F=4.37, p=0.01, O R$ $[\mathrm{IC}]=5.30[1.34-20.99])$.

\subsubsection{Ear positions}

As the ear positions were recorded only when horses ate roughage or straw, the parameter related to roughage (number of hay meals), was not included in the following analyses.

\section{Prevalence of backward ears}

Only one management parameter appeared to be significant concerning the backward ears position: the number of visible neighbours $(\mathrm{F}=5.38, \mathrm{p}=0.005)$. Horses that were allowed limited visual contacts with congeners ([0-1] visible neighbours: OR [IC] =3.68 [1.76-7.71]; [2-4] visible neighbours: OR [IC] $=2.08[1.01-4.30]$ ) presented more backwards ears. On the contrary, horses that could see more than 5 congeners $(\mathrm{OR}=1)$ had less backward ears position (Table 1.).

Seeing [0-1] neighbours appeared to be more important (RI=3.67) than seeing [2-4] neighbours ( $\mathrm{RI}=2.08)$. 
The exact opposite results appeared for predominant forwards ears.

No interaction emerged for these models.

\subsubsection{Presence of "depressed-like" posture in the box}

No clear management parameter emerged as being especially influential here ( $p>0.05$ in all cases). It may be because this "syndrome" results from a combination of varied factors or because an important management factor was not examined here.

\subsection{Study 2: Integrating working conditions}

\subsubsection{Population}

A subset of 276 horses out of the 306 animals mentioned above, coming from 17 of the 20 riding schools $(\bar{X} \pm \mathrm{se}=16.2 \pm 2.1$ horse/school) could be observed during beginners' riding lessons. This second group was constituted of 118 mares, 158 geldings, aged 3-30 y.o. $(\bar{X} \pm$ se $=11.8 \pm 0.3$ ) from 23 breeds (39\% unregistered, 27\% French Saddlebreds and smaller proportions of other breeds). Most of the animals were horses (N=163, 59\%) and $113(41 \%)$ were ponies. The riding lessons were recorded using a Sony HDR-XR105® camera with the protocol developed in Lesimple et al. (2010). Each time the horse-rider couple crossed perpendicularly the camera's field of vision, we recorded the rider's hands' height and reins length, shown as reliable predictors of vertebral disorders in Lesimple et al. (2010)'s study. From these observations, we calculated the time horses were ridden with high hands and short reins. Based on the data distribution, 3 categories were made for each of the parameters (Table 1).

On the 276 horses observed in this part of the study, 35.9\% ( $\mathrm{N}=99)$ expressed at least one $\mathrm{SB} / \mathrm{ARB}, 71.4 \%(\mathrm{~N}=197)$ presented wounds linked to bad fitted equipment, $40.2 \%(\mathrm{~N}=111)$ had mostly ( $>60 \%$ time) backwards ears, 34\% (N=94) had mostly (>60\% time) forwards ears and $41.3 \%(\mathrm{~N}=114)$ presented a "depressed-like" posture in the box. This subset was therefore representative of the whole population.

\subsubsection{Presence of equipment-related wounds}

Five of the investigated management parameters appeared as significant on the prevalence of equipment-related wounds: the type of equine $(\mathrm{F}=9.05, \mathrm{p}=0.003)$, the time ridden with short reins $(\mathrm{F}=6.11, \mathrm{p}=0.003)$, being released alone or in group $(\mathrm{F}=5.26, \mathrm{p}=0.023)$, the number of visible congeners $(\mathrm{F}=3.47, \mathrm{p}=0.033)$ and the number of concentrate meals $(\mathrm{F}=5.13, \mathrm{p}=0.007)$. 
Animals ridden more than $40 \%$ of time with short reins were more at risk to develop equipment-related wounds ([40-65]\%: $(\mathrm{OR}[\mathrm{IC}]=4.97$ [1.66-14.89]) or [73-93] \% :(OR [IC] $=6.93$ [2.36-20.38]), than those ridden [33-39] \% time with short reins (Table 1.) (Fig. 2). The animals ridden more than 70\% with short reins (OR [IC] =6.93 [2.36-20.38]), fed [3-6] meals $(\mathrm{OR}[\mathrm{IC}]=5.69$ [1.79-18.08]), released alone in paddock $(\mathrm{OR}[\mathrm{IC}]=3.34[1.18-9.39])$, and horse type $(\mathrm{OR}[\mathrm{IC}]=2.82[1.45-5.46])$ were more prone to develop equipment related wounds.

Being ridden more than $70 \%$ of the time with short reins appeared as the most important factor (RI: 6.96), followed by the number of concentrate meals (RI: 5.70), being ridden more than $40 \%$ time with short reins (RI: 4.95), the number of visible neighbours (RI: 3.63) and being a horse (RI: 2.83$)$.

\subsubsection{Presence of SB/ARB}

Seven management parameters appeared to significantly impact the prevalence of SB/ARB: the type of equine $(\mathrm{F}=17.32$, $\mathrm{p}<0.0001)$ (Fig. 3.), the time ridden with short reins $(\mathrm{F}=12.49$, $\mathrm{p}<0.0001)$, the box size $(\mathrm{F}=10.5, \mathrm{p}=0.001)$, the litter $(\mathrm{F}=4.16, \mathrm{p}=0.04)$, the possibility of putting the head outside $(\mathrm{F}=3.13, \mathrm{p}=0.045)$ and the number of hay meals $(\mathrm{F}=3.11, \mathrm{p}=0.027)$. Animals ridden [40-65] \% of the time with short reins were more prone to develop SB/ARB than those ridden [33-39] \% of the time with short reins (Table 2.).

The animals ridden [40-65]\% time with short reins (OR [IC] =6.5 [1.66-25.27]), with shaving litter (OR [IC] =6.33 [1.11-36.2]), fed only 1 hay meal (OR[IC]=4.47[1.05-18.99]), o f horse type $(\mathrm{OR}[\mathrm{IC}]=4.19[2.08-8.46])$, and released alone in paddocks $(\mathrm{OR}[\mathrm{IC}]=3.63[1.47-8.97])$ were more prone to develop stereotypic behaviours..

The number of hay meals appeared as the most important parameter (RI: 5.99), followed by the possibility of putting the head outside the box (RI: 5.31), the type of equine (RI: 4.62), the box size (RI: 4.18), the modality of paddock release and the litter (RI: 3.63 for each) and the time ridden with short reins (RI: 2.69).

\subsection{4. "Depressed-like" posture in the box}

Although riding parameters had no direct influence, when they were included in the analysis, the proportion of animals presenting them tended to change according to these parameters $(\mathrm{F}=2.33, \mathrm{p}=0.09)$. However, as this factor is not statistically significant, it was not possible to go further in the statistics and to determine the impact, positive or negative, of each modality 
(dolichomorphic, mesomorphic, brachymorphic) on the prevalence of the depressed-like" posture.

\section{Discussion}

This study is, to our knowledge, the very first to investigate in details the relative impact of several management parameters, including working conditions, type of equines and detailed housing, feeding and social conditions on different expressions of welfare alteration in the same population of horses. The prevalence of equipment related wound was very high, compared to other studies (Burn et al., 2010a: 2-53\%; Pritchard et al., 2005: 13.2-31.9\% of the horses, depending on the location of the lesions), whilst the welfare indicators recorded were in accordance with previous studies (SB/ARB, observational studies: Benhajali et al., 2010; Hausberger et al., 2007, 2009; Lesimple and Hausberger, 2014; Visser et al., 2008; Waters et al., 2002: 22-96.6\%; “depressed-like posture”: Burn et al., 2010a: 2-63\%; Fureix et al., 2012: 24\%).

Amongst the 17 management parameters investigated, 13 influenced significantly at least one of the welfare indicators recorded. When the riding parameters were not taken into account, our results confirmed the importance of feeding (Benhajali et al., 2008; Cooper et al., 2005; Jonsson and Egenval, 2006; Murray et al., 1996; Nicol et al., 2005; Tinker et al 1997), paddock release (Christensen et al., 2002; Heleski et al., 2002; Visser et al., 2008) and social opportunities (Christensen et al., 2002; McAfee et al., 2002; Mills and Riezebos, 2005), and highlighted the emergence of often under-estimated parameters such as the type of equid and the possibility to put the head outside the box. The relative importance of each management parameter varied according to the welfare indicators concerned: the time spent in paddock, type of equids and feeding conditions appear as particularly relevant concerning the prevalence of SB/ARB and equipment-related wounds, whereas visual social opportunities was the only criterion emerging for the ear position when feeding, and no particular parameter emerged to explain the "depressed-like" posture. When including the riding parameters, they appeared as the second most influential parameter, just after the type of equid, and before the paddock release, the feeding and social parameters. It is thus very important to include riding parameters when investigating welfare in riding horses. Previous epidemiological surveys investigating the impact of management parameters were mainly focused on the prevalence of SB/ARB and based upon questionnaires. However, despite the methodological differences, a roughage based diet with regular meals, less constraining working methods, and an increased time spent in paddock were consensually identified as protecting from SB/ARB emergence 
(Normando et al., 2011; McGreevy et al., 1995). In addition, in McGreevy et al. (2005)'s study, when there were grilles or bars between the stalls, horses were less prone to develop any SB/ARB.

In general, our population presented a high prevalence of welfare impairment signals (wounds, SB/ARB, "depressed-like” posture and backwards ears). The proportion of horses suffering equipment-related wounds was higher than those observed in horses working in developing countries (Burn et al., 2010a, 2010b). In these studies, only "severe" lesions were recorded, i.e. involving more or less deep incision of the skin. In our study, no severe lesion was seen, but all the minor flesh lesions including hairs used but skin not incised were recorded, which could explain the differences between the evaluations. Trying to give the horse a living environment the more alike natural conditions is part of welfare improvement. Thus, it is commonly recognised that a roughage based diet has a positive impact on horses' welfare, both from a behavioural (Benhajali et al., 2008; Cooper et al., 2005; Tinker et al., 1997; Jonsson and Egenvall, 2006) and physiological (e.g. Harris, 2007; Nicol, 2000; Nicol et al., 2002) point of view. The dietary physiology of horses is adapted to a high fibre / low energetic intake (Harris, 2007; Martin-Rosset, 2008) and according to most authors, the high prevalence of concentrates and the lack of roughage (i.e. fibres) in the diet of domestic horses is related to a high occurrence of colic, gastric ulcerations, laminitis (Tinker et al., 1997; Jeffcott et al., 1986; Murray et al., 1996; Jonsson and Egenvall, 2006) and SB/ARB (Bachmann et al., 2003; McGreevy et al., 1995; Nicol 1999). In our study, horses that received more roughage meals were less prone to develop $\mathrm{SB} / \mathrm{ARB}$, and those that received more concentrates were more prone to have equipmentrelated wounds. This second relation is less intuitive. Two reasons however may explain this relation: firstly concentrates are highly energetic (Martin Rosset 2008; Tinker et al 1997), and secondly being stuck in a $9 \mathrm{~m}^{2}$ space increases the risk of active locomotion patterns when outside the box (Lesimple et al., 2011). Thus, both the overflow of energy due to concentrates and motion restriction related to box housing might increase the undesired behaviours and unwillingness to slow down at work, leading the riders to have stronger actions on the bit, through the reins. The possibility also exist that overfed horses become fat, and develop wounds at the level of the girth. The opportunity to move freely is an important feature of horses' life: under natural conditions and when allowed to, horses spend in average $90 \%$ of their time grazing (Waring 2003), which means eating while walking (Houpt, 2005). Most of the authors agree that living in a paddock or pasture is more appropriate than living in a box: horses housed in paddocks are less aggressive towards humans (Rivera et al., 2002) and 
develop les SB/ARB (Chaya, 2006; Christensen et al., 2002) than those housed in boxes. This is in accordance with our study: the more horses spent time in a paddock, the less they were prone to develop SB/ARB. The ability to move freely when in paddocks might also explain the lower prevalence of equipment-related wounds: horses having the opportunity to move freely most of the day, they may be less impacted by the working constraints. On the other hand, horses housed in single box, whose only opportunity to move is when ridden could be more reluctant to obey when at work. Increasing social inputs was also shown as improving horse welfare (McAfee et al., 2002; Mills \& Riezebos, 2005). Thus, horses housed with congeners are less prone to develop SB/ARB (Christensen et al., 2002; Visser et al., 2008) and increasing the possibility of visual contact (Mills and Riezebos, 2005; McGreevy et al., 1995) has been shown to have, to a lesser extent, the same positive effect. This is in accordance with our findings, that horses released in paddock with congeners are less prone to develop SB/ARB and wounds, and that increasing visual contacts favours forwards ear position. However, increasing visual horizon towards moving congeners or inaccessible space might increase horses' frustration, whereas close contact to the neighbours (through grids for example) might be more positive (Benhajali et al., 2014; Hausberger et al., in prep; Mills and Riezebos, 2004), which could explain the lowest risks for stereotypic behaviours when horses could not put the head outside (those that did were in general in indoor barns where they faced several congeners at close distance). Working conditions are known to impact horses' welfare (Burn et al., 2010a; Hausberger et al., 2009, 2011; Lesimple et al., 2010; 2012; Fonseca et al., 2006; Visser et al., 2014), but, apart from veterinarian studies, rarely taken into account as part of the management parameters. If the effect of the discipline has already been investigated (Fonseca et al., 2006; Hausberger et al., 2007, 2011), the impact of restrictive riding techniques (short reins and high hands leading to an increased pressure in the horse's mouth and on its neck, Lesimple et al 2010, subm.) has recently been shown as crucial for the prevalence of back disorders (Lesimple et al., 2010, 2012). Here the data confirm earlier findings showing that beginners in riding lessons may alter the spine of the horse (and its mouth) by in particular riding with high hands and tensed short reins (Lesimple et al., 2010, subm). It is crucial that riding teachers be made aware of this as they can thus put more emphasis on riders' positions during lessons (Lesimple et al 2010, in prep). This study highlights that restrictive riding appears amongst the two most important parameters in the emergence of SB/ARB and equipment-related wounds. More interesting still is the fact that when adding the working conditions, not only the models are strengthened but also, the type of equine and the riding techniques (time riders spend with short reins) appear as the two most 
important factors involved in welfare impairment, and interactions emerged between these two parameters. Thus, in addition of being more prone to develop stereotypic behaviours and wounds than ponies, horses are also more sensitive to harmful riding techniques and constraining life conditions. Finally, this study confirms the low impact of sex (Fureix et al., 2010, 2011; Hausberger et al., 2004; Lesimple et al., 2010, 2011, 2012) and age (Cooper et al., 2000; Fonseca et al., 2006; Fureix et al., 2010, 2011; Hausberger et al., 2004; Haussler et al., 1999; Lesimple et al., 2010, 2011, 2012) on horse welfare. However, even if it was not possible to test a potential breed effect here despite its interest (Hausberger et al 2004; Lesimple et al 2011), we show for the first time that in these domestic situations, horses are more at risk to develop stereotypic behaviours and wounds than ponies, which may reflect more difficulties dealing with sub optimal conditions.

These results highlight the multifactorial nature of welfare, both in terms of causes and of consequences on the animals. It is thus of primary importance to take into account the whole management (not in a parameter by parameter approach) and several modalities of welfare expression when trying to investigate the quality of a system. This study allows the classification of management parameters leading to potential "positive" management strategies and enabling to identify "at risk" management strategies in terms of welfare, based on scientific evidence on a large population of horses, and highlights the key points professionals should take care of to improve their horses' welfare.

\section{Acknowledgments}

The authors thank the owner and staff of the riding schools for allowing us to work with their horses and for their understanding. This study was supported by grants from the Caisse Centrale de la Mutualité Sociale Agricole and the French Research Ministry. The funders had no role in the studies design, data collection and analyses, decision to publish or preparation of the manuscript. The authors report no conflicts of interest.

\section{Ethical note}

This study complies with the French laws related to animal experimentation and the European directive 86/609/CEE and were approved by the University of Rennes 1 local Animal Care Committee any time approval was needed. Horse husbandry and care were under management of the riding schools: the horses used in this experiment were not research animals. 
568

569

570

571

572

573

574

575

576

577

578

579

580

581

582

583

584

585

586

587

588

589

590

591

592

593

594

595

596

597

598

599

600

\section{References}

Altman, J., 1974. Observational study of behaviour: Sampling methods. Behaviour, 49, $227-$ 267.

Bachmann, I., Audige, L., Stauffacher, M., 2003. Risk factors associated with behavioural disorders of crib-biting, weaving and box-walking in Swiss horses. Equine Vet. J. 35, $158-163$.

Bashaw, M., Tarou, L., Maki, T., Maple, T., 2001. A survey of assessment of variables related to stereotypy in captive giraffe and okapi. Appl. Anim. Behav. Sci. 73, 235-247.

Benhajali, H., Richard-Yris, M.A., Leroux, M., Ezzaouia, M., Charfi, F., Hausberger, M., 2008. A note on the time budget and social behaviour of densely housed horses - A case study in Arab breeding mares. Appl. Anim. Behav. Sci. 112, 196-200.

Benhajali, H., Richard-Yris, M.A., Ezzaouia, M., Charfi, F., Hausberger, M., 2009. Foraging opportunity: a crucial criterion for horse welfare? Animal 3, 1308-1312.

Benhajali, H., Richard-Yris, M-A., Ezzaouia, M., Charfi, F., Hausberger, M., 2010. Factors influencing conception rates of Arab mares in Tunisia. Anim. Reprod. Sci. 117, 106110.

Benhajali, H., Ezzaouia, M., Lunel, C., Charfi, F., Hausberger, M., 2013. Temporal feeding pattern may influence reproduction efficiency, the example of breeding mares. PLoS ONE, 8(9): e 73858. doi:10.1371/journal.pone.0073858.

Benhajali, H., Ezzaouia, M., Lunel, C., Charfi, F., Hausberger, M.,2014. Stereotypic behaviours and mating success in domestic mares. Appl. ANim. Behva. Sci. 153, 36-42.

Bouissou, M.F., Boissy, A., Veissier, I. 2001. The social behaviour of cattle. In: Keeling, LJ., Gonyou, H.W. (Eds.), Social Behaviour in Farm Animals. CABI Publishing, Wallingford, UK, pp. 113-145.

Burn, C.C., Dennison, T.L., Whay, H.R. 2010a. Environmental and demographic risk factors for poor welfare in working horses, donkeys and mules in developing countries. Vet. J. $186,385-392$.

Burn, C., Dennison, T? Whay, H., 2010b. Relationships between behavior and health in working horses, donkeys, and mules in developing coutries. Appl. Anim. Behav. Sci. 126, 109-118.

Casamassima, D., Sevi, A., Palazzo, M., Ramacciato, R.Collela, G.,E., Bellitti, A., 2001. Effects of two different housing systems on behaviour, physiology and milk yield of Comisana wews. Small Ruminant Res. 41, 151-161. 
Chabchoub, A., Landolsi, F., Jary, Y., 2004. Etude des paramètres morphologiques de chevaux Barbes de Tunisie. Revue Med. Vet. 155, 31-37.

Chaya, L., E. Cowan, \& B. McGuire, 2006. A note on the relationship between time spent in turnout and behaviour during turnout in horses (Equus caballus). Appl. Anim. Behav. Sci. 98, 155-160.

Christensen, J., Ladewig, J., Sondergaard, E., Malmkvist, J., 2002. Effects of individual versus group stabling on social behaviour in domestic stallions. Appl. Anim. Behav. Sci. 75, 233-248.

Cooper, J.J., McDonald, L., Mills, D.S., 2000. The effect of increasing visual horizons on stereotypic weaving: implications for the social housing of stabled horses. Appl. Anim. Behav. Sci. 69, 67-83.

Cooper, J., McCall, N., Johnson, S., Davidson, H., 2005. The short-term effects of increasing meal frequency on stereotypic behavior of stabled horses. Appl. Anim. Behave. Sci. 90, 351-364.

Fonseca, B.P.A., Alves, A.L.G., Nicoletti, J.L.M., Thornassian, A., Hussni, C.A., Mikail, S., 2006. Thermography and ultrasonography in back pain diagnosis of equine athletes. J. Equine Vet. Sci. 26, 507-516.

Freire, R., Clegg, H., Buckley, P., Friend, M., McGreevy, P. 2009. The effects of two different amounts of dietary grain on the digestibility of the diet and behavior of intensively managed horses. Appl. Anim. Behav. Sci. 117, 69-73.

Fureix, C. 2009. Réactions à l'homme et bien-être / mal-être chez le cheval Equus caballus. Vers des indicateurs. Thèse de l'Université de Rennes 1.

Fureix, C., Menguy, H., hausberger, M., 2010. Partenrs with bad temper : reject or cure ? A study of chronic pain and aggression in horses. PLoS ONE 5(8), e12434. doi:10.1371/journal.pone.0012434.

Fureix, C., Gorecka-Bruzda, A., Gautier, E., Hausberger, M., 2011b. Cooccurence of yawning and stereotypic behavior in horses (Equus caballus). ISRN Zool. 2011 doi:10.5402/2011/271209.

Fureix. C., Jego ; P. ? Henry, S., Lansade, L., Hausberger, M., 2012. Towards an ethological model of depression? A study on horses. PLoS ONE 7, e39280. doi:10.1371/journal.pone.0039280.

Fureix, V., Beaulieu, C., Argaud, S., Rochais, C., Quinton, M., Henry, S., Hausberger, M., Mason, G ., 2015. Investing anhedonia in a non-conventional species : do someriding school horses Equus caballus display symptoms of depression? Appl. NAim., Behva., Sci. 162, 26-36. 
Grignard, L., Boissy, A., Boivin, X., Garel, J.P., Le neindre, P., 2000. The social environment influences the behavioural repsonses of beef cattle to handling. Appl. Anim. Behav. Sci. $68,1-11$.

Harris, P., 2007. How should we feed horses- and how many times a day? Vet. J. 173, 252253.

Hausberger, M., Muller, C., 2002. A brief note on some possible factors involved in the reactions of horses to humans. Appl. Anim. Behav. Sci. 76, 339-344.

Hausberger, M., Bruderer, U., Le Scolan, N., Pierre, J.S., 2004. Interplay between environmental and genetic factors in temperament/personality traits in horses (Equus caballus). J. Comp. Psychol. 118, 434-446.

Hausberger, M., Henry, S., Larose, C., Richard-Yris, M.A., 2007. First suckling: a crucial event for mother-young attachment? An experimental study in horses (Equus caballus). J. Comp. Psychol. 121, 109-112.

Hausberger, M., Gautier, E., Biquand, V., Lunel, C., Jego, P., 2009. Could work be a source of behavioural disorders? A study in horses. PloS ONE 4, e7625.

Hausberger, M., Muller, C. \& Lunel, C. 2011. Does work affect personality? A study in horses. PLoS ONE, 6(2), 1-5.

Haussler, K.K., Stover, S.M., Willits, N.H., 1999. Pathologic changes in the lumbosacral vertebrae and pelvis in Thoroughbred racehorses. Am. J. Vet. Res. 60, 143-153.

Heleski, C.R., Shelle, A.C., Nielsen, B.D., Zanella, A.J., 2002. Influence of housing on weanling horse behavior and subsequent welfare. Appl. Anim. Behav. Sci. 78, 291-302.

Hockenhull, J., Creighton, E., 2010. Equipment and training risk factors associated with ridden behavior problem in UK leisure horses. J. Vet. Behav. 5, doi:10.1016/j.jveb.2009.09.019.

Hockenhull, J., Creighton, E., 2012. Equipment and training risk factors associated with ridden behaviour problems in UK leisure horses. Appl. Anim. Behav. Sci. 137, 36-42.

Houpt, K.A., 2005. Maintenance Behaviours. The Domestic Horse; the Evolution, Development and Management of its behaviour. Cambridge University Press, pp. 94108 .

Jeffcott, L.B., Field, J.R., McLean, J.G., O’Dea, K., 1986. Glucose tolerance and insulin sensitivity in ponies and Standardbred horses. Eq. Vet. J. 18, 97-101.

Jonsson, H., Egenval, A., 2006. Prevalence of gastric ulceration in Swedish Standardbreds in race training. Eq. Vet. J. 38, 209-213.

Keiper, D., 1968. Causal factors of stereotypies in caged birds. Anim. Behav. 17, 114-119. 
Lesimple, C., Hausberger, M., 2014.How accurate are we at assessing others' well-being? the example of welfare assessment in horses. Front. Psychol. 5, 1-6. doi: 10.3389/fpsyg.2014.00021.

Lesimple, C., Fureix, C., Menguy, H., Hausberger, M., 2010. Human direct actions may alter animal welfare, a study on horses (Equus caballus). PLoS ONE 5, e10257. doi:10.1371/journal.pone.0010257.

Lesimple, C., Feureix, C., LeScolan, N., Richard-Yris, M.A., Hausberger, M., 2011. Housing conditions ans breed are associated with emotionality and cognitive abilities in riding school horses. Appl. Anim. Behav. Sci. 129, 92-99.

Lesimple, C., Fureix, C., De Margerie, E., Sénèque, E., Menguy, H. Hausberger, M., 2012. Towards a Postural Indicator of Back Pain in Horses (Equus caballus). PLoS ONE 7, e44604. doi:10.1371/journal.pone.0044604.

Main, D., Whay. R,. Green, L.E., Webster. A.J., 2003. Effect of the RSPCA Freedom food scheme on the welfare of dairy cattle. Vet. Rec. 153, 227-231. doi:10.1136/vr.153.8.227.

Martin-Rosset, W., 2008. Energy requirements and allowance of exercising horses. Nutrition of the exercising horse. Wageningen Accademic Pub, pp 103-138.

Mason, G.J., 1991b. Stereotypy: a critical review. Anim. Behav. 41, 1015-1038.

McAfee, L.M., Mills, D.S., Cooper, J.J., 2002. The use of mirrors for the control of stereotypic weaving behaviour in the stabled horse, Appl. Anim. Behav. Sci. 78, 159173.

McBride, S., Long, L., 2001. Management of hrses showing stereotypic behaviour, owner perception and the implication for welfare. Vet. Rec. 148, 799-802.

McGreevy, P.D., Cripps, P.J., French, N.P., Green, L.E., Nicol, C.J., 1995a. Management factors associated with stereotypic and redirected behavior in the thoroughbred horse. Equine Vet. J. 27, 86-91.

Meehan, C.L., Garner, J.P., Mench, J.A., 2003. Environmental enrichment and development of cage stereotypy in orange-winged amazon parrots (Amazona amazonica). Dev. Psychobiol. 44, 209-218.

Meunier-Salaün, M.C., Vantrimponte, M.N., Raab, A., Dantzer, R., 1987. Effect of floor area restriction upon performance, behavior and physiology of growing-finishing pigs. J. Anim. Sci. 64, 1371-1377.

Mills, D.S., 2005. Repetitive movement problems in the horse. In: Mills, D.S., McDonnell, S.M. (Eds.), The Domestic Horse, The Origins, Development and Management of its Behaviour, Cambridge University Press, Cambridge, pp. 212-227. 
Mills, D.S., Riezebos, M., 2005. The role of the image of a conspecific in the regulation of stereotypic head movements in the horse. Appl. Anim. Behav. Sci. 91, 155-165.

Mills, D., Alston, R., Rogers, V., Longford., 2002. Factors associated with the prevalence of stereotypic amongst Thoroughbred horses passing through auctioneer sales. Appl. Anim. Behave. Sci. 78, 115-124.

Murray, M.J., Eichorn, E.S.. 1996. Effects of intermittent feed deprivation, intermittent feed deprivation with ranitidine administration, and stall confinement with ad liitum access to hay on gastric ulceration in horses. Am J Vet Res; 11, 1599-1603.

Napolitano, F., De Rosa, G., Braghieri, A., Grasso, F., Bordi, A., Wemelsfeder, F., 2008. The qualitative assessement of responsiveness to environmental challenges in horses and ponies. Appl. Anim. Behav. Sci. 109, 342-354.

Nicol, C.J., 1999. Understanding equine stereotypies. Equine Vet. J. Suppl. 28, 20-25.

Nicol, C.J., 2000. Equine Stereotypies. In: Houpt. K.A. (Ed.), Recent Advances in Companion Animal Behavior Problems. Ithaca: International Veterinary Information Service. (http://www.ivis.org/advances/Behavior_Houpt/nicol/chapter_frm.asp?LA=1).

Nicol, C.J., Davidson, H.P.D., Harris, P.A., Waters, A.J., Wilson, A.D., 2002. Study of cribbiting and gastric inflammation and ulceration in young horses. Vet. Rec. 151, 658-662.

Nicol, C.J., Badnell-Waters, A.J., Bice, R., Kelland, A., Wilson, A.D., Harris, P.A., 2005. The effects of diet and weaning method on the behaviour of young horses. Appl. Anim. Behav. Sci. 95, 205- 221.

Normando, S., Canali, E., Ferrante, V., Verga, M., 2002. Behavioral problems in italian saddle horses. J. Eq. vet. Sci. 22, 117-120.

Normando, S., Meers, L., Samuels, W.E., Faustini, M., Odberg, F.O., 2011. Variables affecting the prevalence of behavioural problems in horses. Can riding style and other management factors be significant? Appl. Anim. Behav. Sci. 133, 186-198.

Ödberg, F.O., 1978. A study of the hearing ability of horses. Equine Vet. J. 10, 82-84.

Parker, M., Goodwin, D., Redheard, E.S., 2008. Survey of breeders' management of horses in Europe, North America and Australia: comparison of factors associated with the development of abnormal behaviour. Appl. Anim. Behav. Sci. 114, 206-215.

Pedersen, G.R., Sondergaard, E., Ladewig, J., 2004. The influence of bedding on the time horses spend recumbent. J. Eq. Vet. Sci. 24, 153-158.

Popescu, S., Diugan, E.A., 2013. the relationship between behavioural and the other welfare indicators of working horses. J. Eq. Vet. Sci. 33, 1-12. 
Pritchard, J.C., Lindberg, A.C., Main, D.C.J., Whay, H.R., 2005. Assessment of the welfare of working horses, mules and donkeys, using health and behaviour parameters. Prev. Vet. Med. 69, 265-283.

Pritchett, L.C., Ulibarri, C., Roberts, M.C., Schneider, R.K., Sellon, D.C., 2003. Identification of potential physiological and behavioral indicators of postoperative pain in horses after exploratory celiotomy for colic. Appl. Anim. Behav. Sci. 80, 31-43.

Raabymagle, P., Ladewig, J., 2006. Lying behaviour in horses in relation to box size. J. Equ. Vet. Sci. 26, 11-17.

Reefmann, N., Kaszas, F.B., Wechsler, B., Gygax, L., 2009 Ear and tail postures as indicators of emotional valence in sheep. Appl. Anim. Behav. Sci. 118, 199-207.

Rivera, E., Benjamin, S., Nielsen, B., Shelle, J., Zanella, A.J., 2002. Behavioral and physiological responses of horses to initial training: the comparison between pastured versus stalled horses. Appl. Anim. Behav. Sci. 78, 235-252.

Tinker, M., White, N.A., Lessard, P., Thatcher, C.D., Plzer, K.D., Davis, B, Carole, D.K., 1997. Prospective study of equine colic risk factors. Equine. Vet. J. 29, 454-458

Upjohn, M., Shipton, K., Pfeiffer, D., Lerotholi, T., Attwood, G., Verheyen, K., 2012. Crosssectional surbey of owner knowledge and husbandry practices, tack and health issues affecting working horses in Lesotho. Eq. Vet. J. 44, 310-318.

van Reenen, C.G., Mars, M.H., Leushuis, I.E., Rijsewijk, F.A.M., van Oirschot, J.T., Blokhuis, H.J., 2000. Social isolation may influence responsiveness to infection with bovine herpesvirus 1 in veal calves. Vet. Microbiol. 75, 135-143.

Vecchioti, G., Galanti, R., 1986. Evidence of heredity of cribbing, weaving and stall walking in thoroughbred horses. Livestock Prod. Sci. 14, 91-95.

Visser, E.K., Ellis, A.D., Van Reenen, C.G., 2008. The effect of two different housing conditions on the welfare of young horses stabled for the first time. Appl. Anim. Behav. Sci. 114, 521-533.

Visser, E.K., Neijenhuis, F., De Graff-Roelfseman, E., Wesselink, H.G.M., de Boer, J., van Wijhe-Kiezebrink, M.C., Engel, B., van Reenen, C.G., 2014. Risk factors associated with health disorders in sport and leisure horses in the Netherlands. J. Anim. Sci. 92, 844-855.

Wallin, L., Strandberg, E., Philipsson, J., Dallin, G., 2000. Estimates of longevity and causes of culling and death in Swedish warmblood and coldblood horses. Livestock Prod. Sci. 63, 275-289. DOI: 10.1016/S0301-6226(99)00126-8.

Waring, G., 2003. Horse Behavior, second edition. Noyes Publications/William Andrew Publishing, Norwich, New York. 
Waters, A., Nicol, C., French, N., 2002. Factors influencing the development of stereotypic and redirected behaviours in young horses: findings of a four year prospective epidemiological study. Equine Vet. J. 34, 572-579.

Wechsler, B., Fröhlich, E., Oester, H., Oswald, T., Troxler, J., Weber, R., Schmid, H., 1997. The contribution of applied athology in judging animal welfare in farm animal housing systems. Appl. Anim. Behav. Sci. 53, 33-43.

Whay, H., Main, D., Green, L.E., Webster. A.. 2003. Assessment of the welfare of dairy cattle using animal-based measurements: Direct observations and investigation of farm records. Vet. Rec. 153, 197-202. 
Tables

Table 1. F values and Odd Ratio of the management parameters and their different modalities included in the logistic regression model of each welfare indicator. The welfare indicators are presented in column and the management parameters in lines. To read the logistic regression model for each indicator, the table has to be read in columns.

\begin{tabular}{|c|c|c|c|c|c|}
\hline & & $\begin{array}{c}\text { SB/ARB } \\
\mathbf{F} \\
\text { OR [IC] } \\
\end{array}$ & $\begin{array}{l}\text { Wounds } \\
\quad \mathbf{F} \\
\text { OR }[\mathrm{IC}]\end{array}$ & $\begin{array}{c}\text { Backw. Ears } \\
\mathbf{F} \\
\text { OR }[\mathrm{IC}]^{\mathrm{b}} \\
\end{array}$ & $\begin{array}{c}\text { Forw. Ears } \\
\mathbf{F} \\
\text { OR }[\mathrm{IC}]^{\mathrm{b}} \\
\end{array}$ \\
\hline \multirow{3}{*}{$\begin{array}{l}\text { Individual } \\
\text { informations }\end{array}$} & Type & $8.60 * *$ & $4.59 *$ & & \\
\hline & Horse & 2.56 [1.39-4.69] & $1.87[1.1-3.2]$ & & \\
\hline & pony & 1 & 1 & & \\
\hline \multirow{7}{*}{$\begin{array}{l}\text { Housing } \\
\text { conditions }\end{array}$} & Type of door & $4.31 *$ & & & \\
\hline & Yes & 1 & & & \\
\hline & Lim & $0.44[0.22-0.85]$ & & & \\
\hline & No & $0.38[0.15-0.96]$ & & & \\
\hline & Time in paddock & $14.12 * * *$ & $7.77 * * *$ & & \\
\hline & {$[0-16.14]$} & $3.69[1.88-7.22]$ & $2.37[1.35-4.18]$ & & \\
\hline & {$[25-83]$} & 1 & 1 & & \\
\hline \multirow{4}{*}{$\begin{array}{c}\text { Social } \\
\text { possibilities }\end{array}$} & Visual contact & & & $3.36 *$ & $3.38^{*}$ \\
\hline & {$[0-1]$} & & & $3.68 \quad[1.76-7.71]$ & $0.42[0.21-0.86]$ \\
\hline & {$[2-4]$} & & & $2.08[1.01-4.30]$ & $0.4[0.2-0.77]$ \\
\hline & [5-more $]$ & & & 1 & 1 \\
\hline \multirow{9}{*}{$\begin{array}{l}\text { Feeding } \\
\text { conditions }\end{array}$} & No hay meals & & $3.75 * *$ & & \\
\hline & {$[0]$} & & $2.44[1.03-5.80]$ & & \\
\hline & [1] & & 2.29 [1.26-4.16] & & \\
\hline & [2] & & 1 & & \\
\hline & {$[3-10]$} & & $0.45[0.14-1.45]$ & & \\
\hline & No concentrate meals & $3.25 *$ & & & \\
\hline & {$[0]$} & 0.12 [0.01-0.95] & & & \\
\hline & [1-2] & 1 & & & \\
\hline & $(3-6]$ & $0.64[0.34-1.2]$ & & & \\
\hline
\end{tabular}

F: F value. $* \mathrm{p}<0.05, * * \mathrm{p}<0.01, * * * \mathrm{p}<0.005$

OR IC[]: Odd Ratio and Confidence Interval.

For the presence of SB/ARB, Wounds, Abn Post, and Backw. Ears modalities with OR $<1$ are increasing horses' welfare

For the Forw. Ears, modalities with OR $>1$ are increasing horses' welfare 
800 Table 2. F values and Odd Ratio of the management parameters, including riding parameters 801 on the presence of SB/ARB, wounds and abnormal postures. The welfare indicators are 802 presented in column and the management parameters in lines. To read the logistic regression 803 model for each indicator, the table has to be read in columns.

\begin{tabular}{|c|c|c|c|c|c|}
\hline & & & $\begin{array}{c}\text { SB/ARB } \\
\mathbf{F} \\
\text { OR }[I C]\end{array}$ & $\begin{array}{l}\text { Wounds } \\
\mathbf{F} \\
\text { OR [IC] }\end{array}$ & $\begin{array}{c}\text { Abn Post } \\
\mathbf{F} \\
\text { OR [IC] }\end{array}$ \\
\hline & Proportion & & & & $2.33^{\circ}$ \\
\hline & & Dolicho. & & & \\
\hline & & Meso. & & & \\
\hline & & Brachy. & & & \\
\hline & Type & & $17.32 * * *$ & $9.05 * * *$ & \\
\hline & & Horse & $4.19[2,08-8,46]$ & $2.82[1.45-5.46]$ & \\
\hline & & Pony & 1 & 1 & \\
\hline & Box's size & & $10.47 * *$ & & \\
\hline & & Large & 1 & & \\
\hline & & Small & $0.18[0,07-0,5]$ & & \\
\hline & Litter & & $4.16 *$ & & \\
\hline Housing & & Straw & 1 & & \\
\hline conditions & & Shaving & $6.33[1.11-36.2]$ & & \\
\hline & Type of door & & $3.13 *$ & & \\
\hline & & Yes & 1 & & \\
\hline & & Lim & $0.38[0.16-0.86]$ & & \\
\hline & & No & $0.37[0.12-1.17]$ & & \\
\hline & Tactile contact & & & & \\
\hline & & Yes & & & \\
\hline & & No & & & \\
\hline & Visual contact & & & $3.47 *$ & \\
\hline Social & & {$[0-1]$} & & $0.27[0.1-0.75]$ & \\
\hline possibilities & & [2-4] & & $0.50[0,17-1,41]$ & \\
\hline & & [5-more] & & 1 & \\
\hline & $\begin{array}{l}\text { Paddock } \\
\text { release }\end{array}$ & & $8.29 * * *$ & $5.26 *$ & \\
\hline & & Alone & 3.63 [1.47-8.97] & 3.34 [1.18-9.39] & \\
\hline & & Group & 1 & 1 & \\
\hline & No hay meals & & $3.11 *$ & & \\
\hline & & [0] & $4.04[1.57-23.22]$ & & \\
\hline & & [1] & 4.47 [1.05-18.99] & & \\
\hline & & [2] & 1 & & \\
\hline conditions & & {$[3-10]$} & $0.22[0.01-2.85]$ & & \\
\hline & No concentrate & meals & & $5.13 * *$ & \\
\hline & & [0] & & $3.60[0.52-24.65]$ & \\
\hline & & {$[1-2]$} & & 1 & \\
\hline & & $(3-6]$ & & 5.69 [1.79-18.08] & \\
\hline & Short reins & & $12.49 * * *$ & $6.11 * * *$ & \\
\hline Working & & [33.64-38.33] & 1 & 1 & \\
\hline conditions & & [40-64.60] & $6.47[1.66-25.27]$ & $4.97[1.66-14.89]$ & \\
\hline & & [73.13-93.54] & $0.98[0.21-4.48]$ & $6.93[2.36-20.38]$ & \\
\hline
\end{tabular}

$\mathrm{F}: \mathrm{F}$ value. $* \mathrm{p}<0.05, * * \mathrm{p}<0.01, * * * \mathrm{p}<0.005$ OR IC[]: Odd Ratio and Confidence Interval.

For the presence of SB/ARB, Wounds, Abn Post, and Backw. Ears modalities with OR $<1$ are increasing horses' welfare

809 For the Forw. Ears, modalities with OR $>1$ are increasing horses' welfare 


\section{Figure captions}

812 Fig. 1. Distribution of the number of hay meals amongst our population of horses: example of 813 categories. The points in black represent the number of horses for each number of meals. The 814 circles in grey represent the categories built on the basis of the data distribution.

815 Fig. 2. Proportion of horses with and without equipment-related wounds according to the time

816 ridden with short reins. The proportion of horses presenting wounds equipment-related

817 increases with the time ridden with short reins.

Fig. 3. Proportion of horses with and without SB/ARB according to the number of hay meals. The proportion of horses with SB/ARB decreases when the number of hay meals increases. 


\section{Figures}

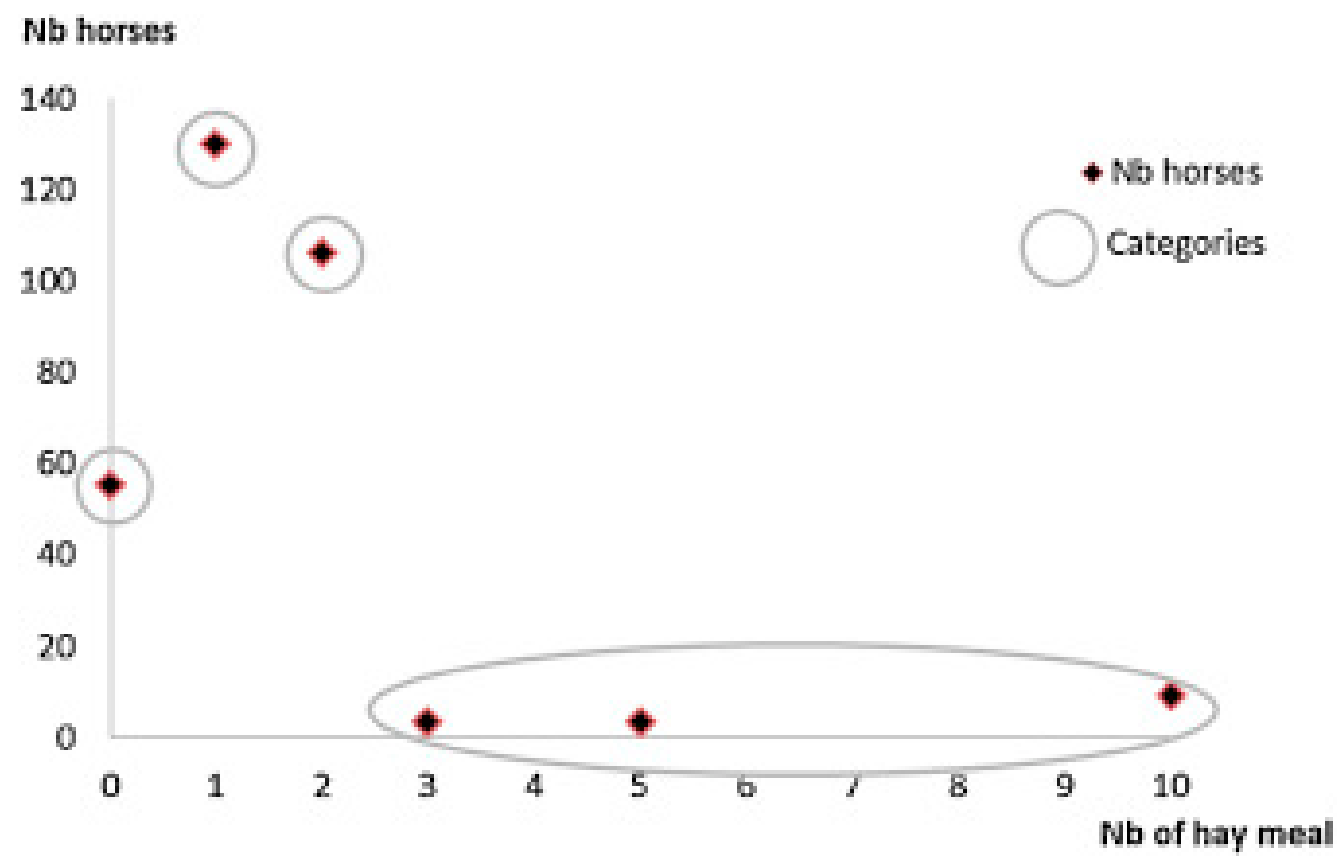

Fig. 1. Distribution of the number of hay meals amongst our population of horses: example of categories. The points in black represent the number of horses for each number of meals. The circles in grey represent the categories built on the basis of the data distribution.

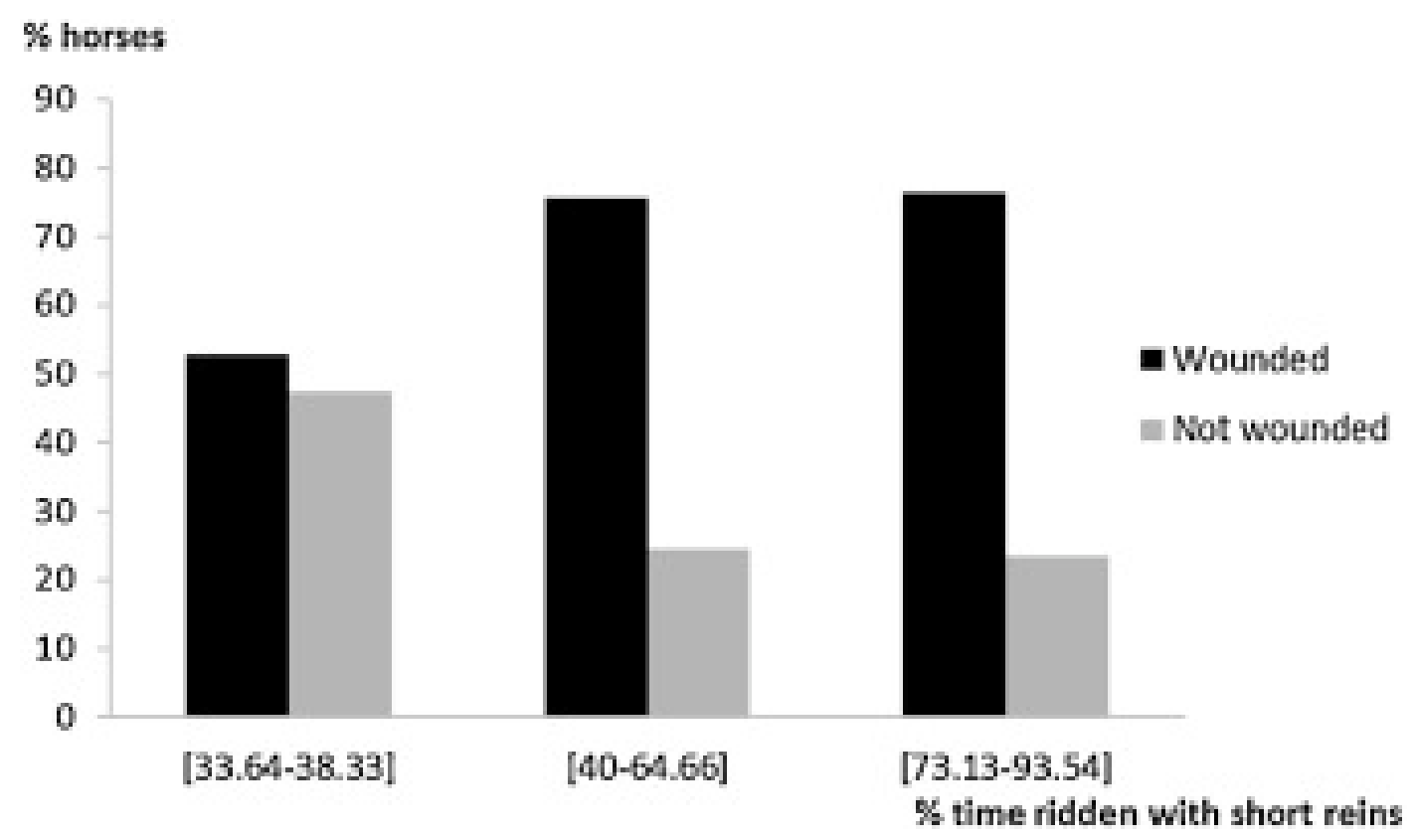

Fig. 2. Proportion of horses with and without equipment-related wounds according to the time ridden with short reins. The proportion of horses presenting wounds equipment-related increases with the time ridden with short reins. 


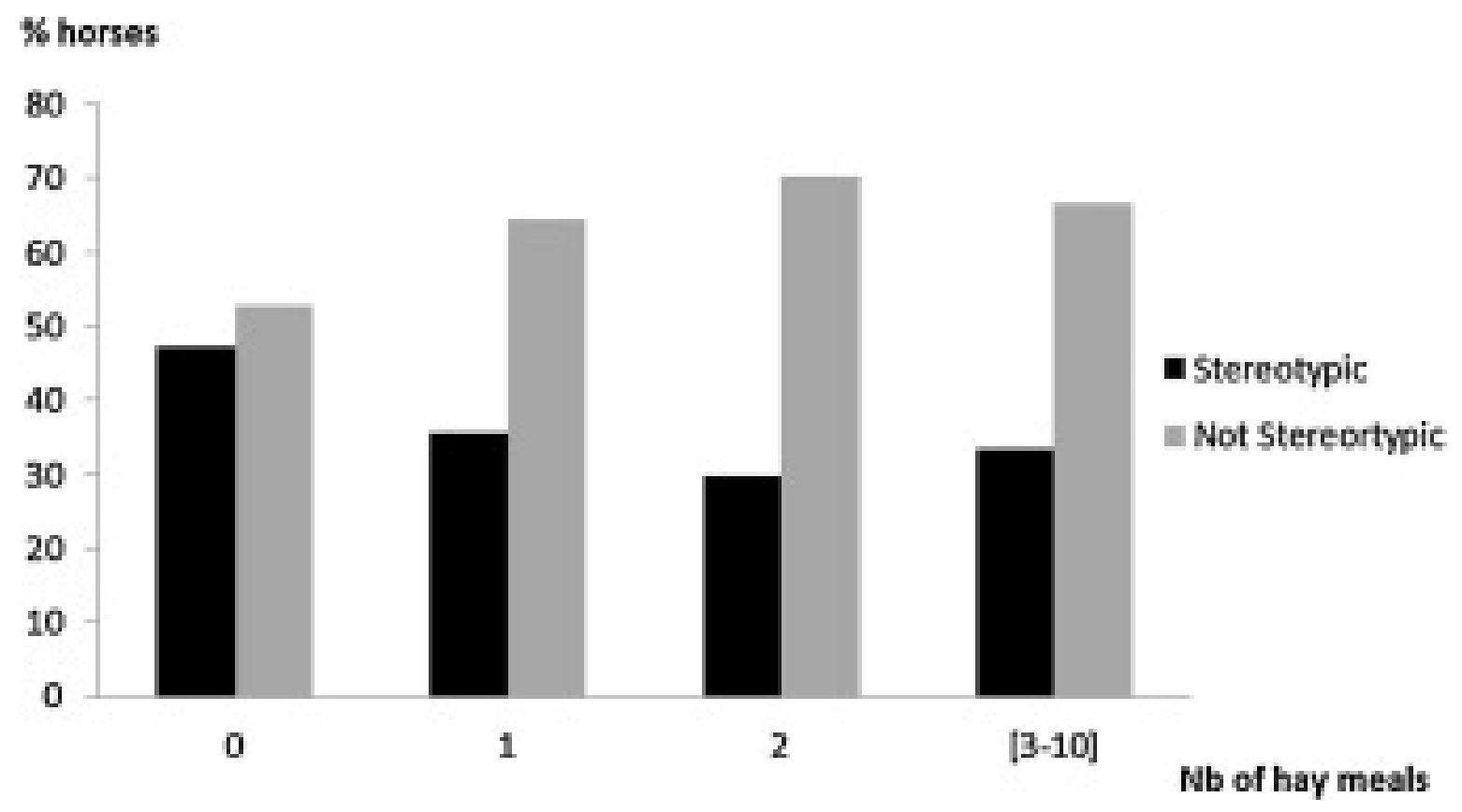

Fig. 3. Proportion of horses with and without SB/ARB according to the number of hay meals. The proportion of horses with SB/ARB decreases when the number of hay meals increases. 